Academic Entrepreneurship for Medical and Health Scientists • Academic Entrepreneurship for Medical and Health Sciences

\title{
A Seat at the Table: Special Considerations for Women and Underrepresented Groups in Academic Entrepreneurship
}

\section{Linda Fleisher ${ }^{1}$, Alexandra Marquez ${ }^{2}$}

${ }^{1}$ PhD, MPH; Fox Chase Cancer Center, ${ }^{2}$ MD, MSTR; Hospital for Sick Children, University of Toronto

Published on: Sep 30, 2019

DOI: $10.21428 / \mathrm{b} 2 \mathrm{e} 239 \mathrm{dc} .618 \mathrm{~b} 909 \mathrm{~b}$

License: Creative Commons Attribution-NonCommercial-NoDerivatives 4.0 International License (CC-BY-NC-ND 4.0). 


\section{Topic Relevance by Timeline}

\section{Summary}

- Women and marginalized groups are underrepresented in STEM-related and entrepreneurial fields

- These populations face many challenges in these fields, including:

- Finding funding sources for their project and/or lacking knowledge of where to obtain funding

- Risking their academic standing if their project is not based on incentives deemed as academic

- Conscious and unconscious bias

- Lack of diverse groups in review and decision-making roles

- Limited access to experienced mentors

- Throughout the chapter are annotations that feature video interviews from my AWARE project to bring the chapter to life and introduce a dialogue about many of the challenges introduced here.

\section{Introduction}

As academic entrepreneurship continues to grow and thrive, the reality that both women and racial and ethnic minorities are sorely underrepresented in these areas is stark and reflective of the challenges these groups face in broader areas of science and business. Women, along with racial and ethnic minorities are often hard to find in science, technology, engineering, and math (STEM)-related programs, academic entrepreneurship programs, and innovation incubators (Etzkowitz and Ranga Landivar; : Noonan; Olsen). (see the chapter "Accelerators and Incubators"). In examining federally funded SBIR/STTR grants and venture capital investment portfolios, these groups are again underrepresented (․ㅡㄹis). (see the chapter "SBIR/STTR Grants: Introduction and Overview" and "Seeking Venture Capital Investment"). Unfortunately, women and minorities have consistently won fewer grants 
than other chdemographic groups. As the FY2012 Report on the National Science Foundation's (NSF) Merit Review Process across NSF suggests, the primary challenge appears to be getting women and minorities "into the pipeline."

In this chapter, we highlight some of the challenges and opportunities faced by women and marginalized groups of color, recognizing that these are not homogeneous groups, and that each group contends with unique issues, as well as individual differences. Although the gender gap persists, in recent years, there has been a considerable effort to address inequality between women and men in STEM fields and entrepreneurship. Compared to women, U.S.-born people of color are even more significantly underrepresented (Mervis). However, many of the challenges are similar across these groups, such as: facing conscious and unconscious bias, having more limited access to training and mentoring, receiving inadequate early financing, and difficulty finding established business networks. They may have already overcome additional barriers in their academic careers that are only exacerbated when considering academic entrepreneurship where the institutional reward system "is not designed to include such pursuits" and these "systems established by men tend to appeal to and serve men's interests" (ㅂowe et al.). (see the chapter "Careers in Academia and Industry: Transitions and Challenges"

Despite the disparities, the number of mentoring and training programs has increased; these programs address the unique needs of those underrepresented groups, with women-focused programs leading the way (Howe et al.; Million Women Mentors Entrepreneurship Initiative Mentoring_Program; Valantine and Sandborg). Mentoring from other successful women and underrepresented groups of academic and business entrepreneurs is essential to address many of the unique cultural issues and barriers. Academic institutions (both in administrative and innovation areas) need to proactively address this disparity and intentionally implement programs and systems to overcome these barriers. In addition, tapping the unique perspectives and underlying resiliency of women and minority academics is important to strengthening and expanding the innovation ecosystem at both the institutional and individual levels. Here, we discuss these challenges and opportunities; we also provide important resources to move us forward in a more diverse and rich environment for innovation.

\section{The Challenge}




\section{Demographics of innovation}

According to the study, Demographics of Innovation, in the U.S., both women and people of color are underrepresented as innovators (Figure 1). Only 12\% of U.S. innovators are women, and an even smaller percentage of that proportion are in STEM programs or are working as scientists and engineers. U.S. born minorities (including Asians, African Americans, Hispanics, Native Americans) make up just 8\% of U.S. born innovators, yet they comprise $32 \%$ of the overall U.S. population (Nager et al.). In a break-down of NIH-sponsored SBIR grants, only $0.3 \%$ of grants were awarded to teams with an African American Principal Investigator (PI), 2\% with a Hispanic PI, and $6.8 \%$ with an Asian PI (Mervis).
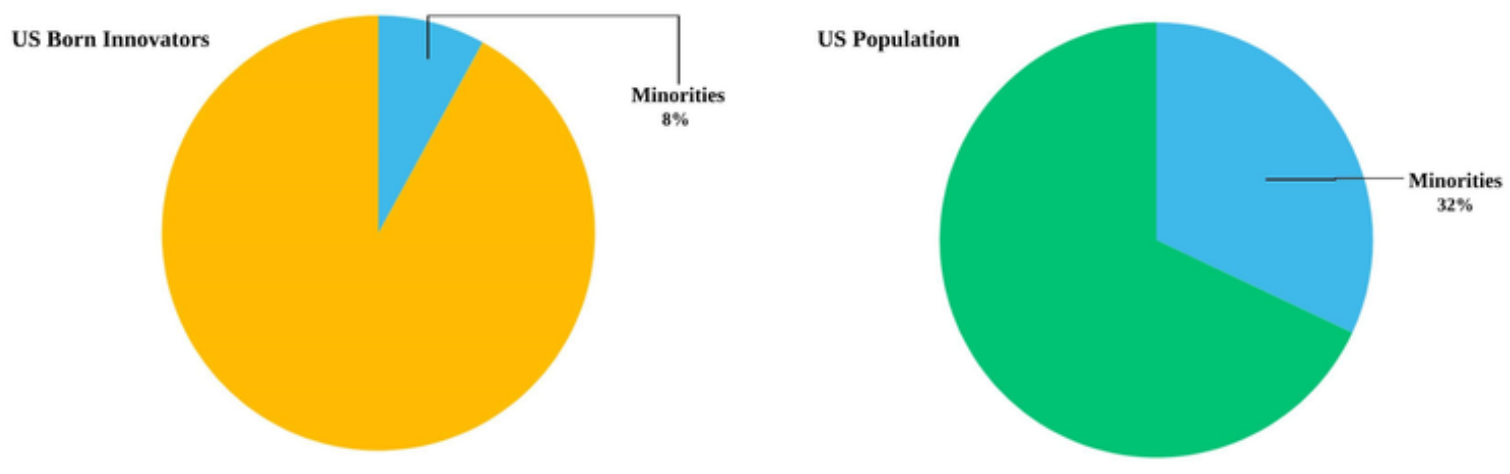

Figure 1

Percentage of Innovator Minorities in Comparison to Population

\section{Adapted from (U.S. Small Business Administration Office of Advocacy.).}

\section{Unique challenges}

The literature, along with our own research, indicates that women and racial/ethnic minorities may experience unique challenges and barriers as they explore opportunities for academic entrepreneurship (Figure 2). These barriers include: a more limited network with access to business and key decision makers; limited awareness and access to funding sources and programs; lack of academic incentives, which might jeopardize hard-earned academic standing; conscious and unconscious bias and lack of diverse groups in review and decision-making roles; and a dearth of mentors, specifically those who can provide personal experience and guidance on how to effectively stand out as a strong applicant in this arena (Howe et al.; Abreu and Grinevich; Ding et al.; Castillo; Xie and Shauman). The Center for American Progress 
(CAP) report highlights how small business creation falls short for these groups (Bahn et al.).

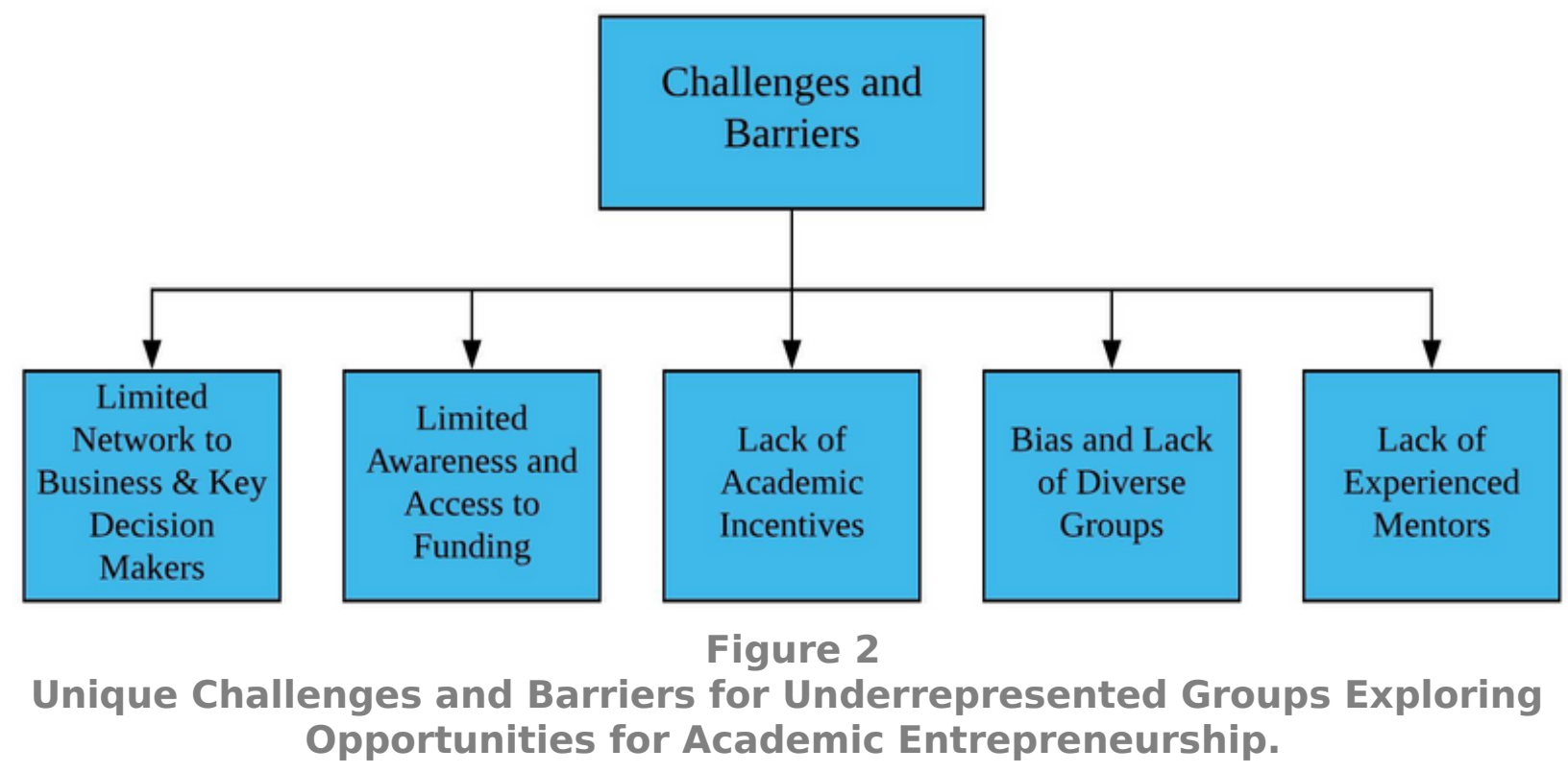

Our own work (AWARE project, National Science Foundation pilot award, Fleisher, PI), which included a series of interviews and meetings with women and minority academics, entrepreneurs, and thought leaders, highlighted many of these challenges, along with the unique attributes that women and minorities bring with their own experience. A woman or person of color who decides to become an entrepreneur often brings with her strengths of vision, determination, passion, and intellect. These are assets that some respondents characterized, and that the research team observed, to be unique to this population, which has had to fight harder to achieve in a very competitive space. (Read more about AWARE in Media Resources at the end of this chapter.)

\section{Limited representation and limited network of business and decision making}

The process of commercialization is a social process, requiring network and human capital. Women have been found to have less access to important networks and R\&D (DeTienne and Chandler). These business and science networks are necessary to establish strong scientific advisories and attract credibility (see the chapter "Effective Networking"). 


\section{Academic challenges}

- "...Someone who says they will leave their profession to take a risk on some IP, it's very difficult to get them to do that..." (Participant Quote, AWARE Project)

- "I still think when I talk about finance and minorities, because of the legacy there's still the vulnerability factor to not having income. You know what I mean, there's not a pot of aunt and uncles money that will pay for the kid's school if I don't get it right. My source of income maybe covers my family and a sibling. All of America can be this way too, but I just think percentage wise, we're higher, more skewed." (Participant Quote, AWARE Project)

- "Until there become more professors of color, you don't have professors coming out of the pipeline that I've seen in universities who are men or women of color. They're not future faculty. They're not folks who are lining up to be our future technology transfers. They're just not there, I haven't seen them. Every presentation that was made last week that was sold was a Caucasian male or an Indian male." (Participant Quote, AWARE Project)

\section{Knowledge and access to start-up funding and knowledge of funding opportunities}

- Banks, venture capitalists, and angel investors are less likely to support female initiated enterprises (Etzkowitz and Ranga $)$.

- One of the first significant barriers that a woman/minority entrepreneur might face is that they may not be aware of opportunities for funding because they have not been "at the table" when ideas are initiated. Several respondents describe knowing that there was a "meeting before the meeting," or that "the pie was cut before they knew there was a pie," or that "it's hard to join a race that's already started." These barriers are often unnoticed by individuals in positions of power. For example, in our efforts to recruit interviewees in our NSF AWARE study, thought leaders we know and spoke to, most of whom were white men or white women, could not provide us with minority entrepreneur contacts because they had not encountered them in the field. However, it became clear that once we found the right individuals to talk to, that barrier was broken, and we connected with multiple individuals in Philadelphia who met our eligibility criteria. As one minority thought leader described, "If you're looking for salt, you need to go to the salt mine." We discovered that many, mostly white decision-makers do not even know that the "salt mine" exists. These thought leaders do not appear to be exercising a conscious effort to leave out minorities and/or women from their networks and business development. Instead, it is as if these minority and/or women entrepreneurs dwell in a parallel universe, where 
robust networking and innovative venture capital and entrepreneurial efforts are underway, often out of the sight of those who are not part of that world.

- "A lot of times black-owned companies don't know about these opportunities. That's probably the first barrier to access is not knowing...If you're not in the room -- there is usually a room before the room. There's always a meeting before the meeting." (Participant Quote, AWARE Project)

\section{Lack of diversity on review panels and innovation boards}

Lack of diversity on selection committees is common and has many ramifications (Morgan et al.; Carnes et al.; Shavers et al.). Funders often have little exposure to entrepreneurs of diverse backgrounds; their professional networks do not include them, and they do know how to find them within other professional networks. As a result, these key decision-makers may not be exposed to the capabilities of other populations and may underestimate the importance that diversity plays in their programs' success. This lack of diversity on selection committees directly and negatively impacts funding success rates for proposals submitted by individuals of minority background ( $\underline{\text { Check Hayden; Reardon). }}$.

- "I've been an NSF reviewer several times, and interestingly enough have written 5 NSF grants- none of which have been funded. Nor have any of my peers, who are women of color and doing exceptional work, been funded. We are very clear that there are dynamics on both sides of this." (Participant Quote, AWARE Project)

- "It is what the eye is looking for that the eye sees." (Participant Quote, AWARE Project)

\section{Limited mentoring particularly addressing cultural and diversity issues}

- Mentoring and tutoring was rated as more important to females than men (Fältholm et al.).

- Creating Entrepreneurs: The impact of Entrepreneurship Programs on Minorities (Lyons and Zhang). found that these types of training can have more pronounced positive impact for women and minorities.

- "I can think of one woman in my whole business career, and probably my medicine career too, that I could count as mentor". (Participant Quote, AWARE Project) 


\section{Conscious and unconscious}

- "It was a story of heartbreak, in that the women that we are investing in- I am them. I am an African American woman, I was raised middle class in Napa, wine country, beautiful idyllic settings. Our summers were beach houses in Southern California. I grew up golfing and skiing and sailing and skydiving. I went to an Ivy League school. I went to a large, reputable, Wall Street firm. Yet, society didn't see me and didn't see the woman I represent. There was heartbreak in that because myself and the woman that I see has for the most part followed the American dream, and yet when society needs the capital market and the financial market, they're not there to meet that." (Participant Quote, AWARE Project)

\section{The Opportunities}

These issues have not gone unnoticed, and although much work remains, many organizations recognize these problems and are actively putting programs, mentoring opportunities and trainings in place to build these pathways for women and people of color. Formal and informal mentoring is also critical for women and minority academics who are interested in exploring entrepreneurial opportunities.

For those of us considering an academic entrepreneurship path it is important to find mentors who are similar to us or who have had similar experiences to complement the business mentors that are essential to success (see the chapter "Careers in Academia and Industry: Transitions and Challenges"). These cultural barriers are significant; finding mentors who understand these barriers and can help to navigate often unfamiliar territory is critical to success.

There is value in partnership - both internally and externally. Academics have tremendous skills and experience in grant writing. Although business funding and SBIR/STTRs are different from research grants, the fundamental skills can be parlayed (see the chapter "Writing the Business Plan for a Life Science Startup"). As we heard from one small business owner,

- "We were successful because our academic founders have written literally a gazillion grants and they know what makes a successful grant and what makes an unsuccessful grant. We kind of followed that formula [under] their guidance."(Participant quote - AWARE Interviews) 


\section{Diversity is the backbone of creativity}

Diversity in disciplines, backgrounds, experiences and perspectives is essential to a creative team that can innovate solutions to difficult problems facing society (see the chapter "Building_a Successful Startup Team"). The insights from women and minority entrepreneurs highlight the importance of diversity.

- "The question of having a diverse source of technology and ideas is a good thing. It's not something that is being done as a favor to anyone. If we are competing as a nation on an international level, if you look at any major scientific discovery, the history is amazing. In which it always has had people from different races, different cultures, different genders, and different sexual orientations. Intelligence is not limited to a particular gender, sexual orientation, or race. Now, I'm open to debate on that. We need to start from the ground now of saying this is a good thing. If we want to succeed, we need to tap into all of our brains. Keeping out a certain portion of society hurts us. This is not about being nice. This is about being the best you can be." (Participant Quote, AWARE Project)

- "If we all think alike then we have no creativity. This is not about being nice, this is about being able to get the best possible minds. Sometimes the best possible minds think in a counter-intuitive manner, and therefore convey information in a manner that you may not necessarily be used to." (Participant Quote, AWARE Project)

\section{Future Directions}

In their report, "A Progressive Agenda for Inclusive and Diverse Entrepreneurship", the Center for American Progress (CAP) examines the barriers facing women and minorities, and then proposes the following progressive policy changes to help "level the playing field" (Bahn et al.).

- Address the wealth gap and expanding access to capital through an enhanced State Small Business Credit Initiative

- Develop an Entrepreneurial Apprenticeship

- Foster early training and education to help young people foster an entrepreneurial spirit

- Utilize the resources of “one stop shops” and Self-Employment Assistance Programs to help people start businesses

- Develop broad progressive economic policies to expand opportunities for entrepreneurship 


\section{Conclusion}

Although entrepreneurship is a promising avenue for job creation and increasing income, structural and economic barriers have prevented women and people of color from having equitable access to necessary resources for starting businesses. Individuals can generate revenue for themselves and their communities through entrepreneurship, if they are given equal access to the capital and education necessary to succeed. Per the CAP report, "Making entrepreneurialism a career choice open to all will help families build wealth; create opportunities for jobs and mobility in disadvantaged communities; and support a robust, inclusive, and growing economy." (Bahn et al.).

\section{Resources}

\section{Mentorship Programs}

E-Mentor Advocate Partnership Program (EMAP). Retrieved from The MIT Office of Minority Education.

- "Through the E-Mentor Advocate Partnership Program (EMAP), OME works closely with the Industrial Advisory Council for Minority Education (IACME) and MIT alumni to promote the direct involvement of industry in the educational development of MIT students. The goal of EMAP is to help students transition from academia to the work environment. IACME mentors work closely with MIT protégés to guide them through the process."

- Mentors: Faculty/Staff

- Mentees: Underrepresented Minorities

GWIP-UWIP Mentoring_Program. Retrieved from MIT Graduate Women in Physics.

- "We will pair up one or two interested undergrads with each grad student mentor, and give her money each month to take you to lunch. It's that simple! If you've ever wished you had someone to give you a little advice about finding a good UROP, answer your questions about what grad school is like, or just assure you that you'll make it through even though you feel overwhelmed with one too many problem sets to finish -- all over an ice cream sundae -- then this program is for you."

- Mentors: Graduates

- Mentees: Women in physics undergrads 
Laureates and Leaders. Retrieved from The MIT Office of Minority Education.

- "The Laureates \& Leaders program is a graduate school initiative designed to encourage and support students, in particular those who are underrepresented in the sciences and engineering, in their quest to achieve a graduate degree."

- Mentors: Faculty/Staff

- Mentees: Underrepresented Minorities

Mentor Advocate Partnership_(MAP). Retrieved from The MIT Office of Minority Education.

- "A volunteer program designed to complement the current advisor system by helping first-year students to build relationships with staff, faculty, graduate students, and post-docs; to monitor their academic performance and personal well-being; to offer encouragement; and to provide a proactive support network."

- Mentors: Faculty/Staff

- Mentees: Underrepresented Minorities

\section{Training Programs}

Foster School of Business: Minority_Business Executive Program

- "This accelerated one-week intensive program is designed to assist minority and women business leaders in facing current and future business challenges. Participants will learn to utilize financial tools to make more effective decisions, develop and understand long-term strategic plans for growth and sustainability, learn how to market their products and services more effectively, manage their processes and projects more efficiently and develop their leadership skills. They return to their business with new skills, a renewed personal energy, and an invaluable network of fellow minority and women business leaders."

Valuable Resources For Minority Entrepreneurs

- From educational opportunities to networking and career development, here are six valuable organizations dedicated to helping diverse entrepreneurs grow and flourish.

\section{Grant Opportunities}

The National Science Foundation (NSF) Innovation "I-Corps" Program

- The NSF I-Corps Program connects underrepresented academic researchers to technological and entrepreneurial communities by providing infrastructure, 
resources, networking and training to move scientific discoveries from university labs to the marketplace. The selected I-Corps sites will use $\$ 30,000$ supplemental awards to pilot novel approaches and partnerships that promote inclusive entrepreneurship through I-Corps. The pilot activities will engage differently-abled individuals, first-generation college students, racial and ethnic minorities and women, as well as Minority-Serving Institutions.

National Cancer Institute (NCI) Center to Reduce Cancer Health Disparities Diversity Training Branch

- The Center to Reduce Cancer Health Disparities (CRCHD) Diversity Training Branch (DTB) within the NCI offers several funding opportunities for students and investigators from diverse populations to "become the next generation of competitive researchers in cancer and cancer health disparities research."

- Continuing Umbrella of Research Experiences (CURE)

- Intramurual Continuing Umbrealla of Research Experiences (iCURE)

- Partnerships to Advance Health Care Equality (PACHE)

National Heart, Lung, and Blood Institute (NHLBI) Mentored Research Scientist Career Development Award (K01) to Promote Faculty Diversity in Biomedical Research

- Enhances the pool of highly trained investigators from diverse backgrounds underrepresented in research areas of interest to the NHLBI. Targeted toward individuals whose basic, clinical, and translational research interests are grounded in the advanced methods and experimental approaches needed to solve problems related to cardiovascular, pulmonary, and hematologic diseases and sleep disorders in the general and health disparities populations.

\section{$\underline{\text { NIH Women of Color Research Network (WoCRn). }}$}

- The purpose of WoCRn is to provide women of color in the biomedical sciences information about the NIH grants process, advice on career development, and a venue or forum for networking and sharing information.

\section{Minority Venture Partners Accelerator}

- Minority Venture Partners is a business acceleration company whose purpose is to increase minority- and women-driven enterprises in emerging technology sectors throughout New York City and the Tri-state Area by providing knowledge, mentors, 
networks, and access to startup capital to bring their innovative products and services to market.

\section{Selected Reading}

Bates, T., Bradford, W.D. \& Seamans, R. (2018). Minority entrepreneurship in twentyfirst century America. Small Bus Econ, 50 (3), 415-427. https://doi.org/10.1007/s11187$\underline{017-9883-5}$

- Examines lingering barriers impeding the development of a more vibrant minority business community. Focusing on access to financing and government procurement markets, articles in this issue offer explicit analyses of enduring barriers, along with explanations of adoptive strategic firm behavior appropriate for reducing those barriers.

Carter, S., Mwaura, S., Ram, M., Trehan, K. \& Jones, T. (2015) Barriers to ethnic minority and women's enterprise: Existing evidence, policy tensions and unsettled questions. International Small Business Journal 33(1), 49-69. https://doi.org/10.1177/0266242614556823

- This article presents an overarching review of the evidence regarding enterprise diversity. It discusses the context of ethnic minorities and women in enterprise and summarizes research evidence relating to their relative access to finance, market selection, and management skills. Policy within the field of diversity and enterprise is characterised by a number of tensions and unresolved questions including the presence of perceived or actual discrimination, the quantity and quality of ethnic minority and women-led businesses, potential market failure in the support provided to diverse enterprises and the substantive uniqueness of ethnic minority and womenled enterprises. Particular implications for policy and practice as well as directions for future research are discussed.

Lopez, A. (2014, June 26). The Solution That Could Help More Minority Entrepreneurs Get Funding. Forbes.

- The objective of this article is to discuss reasons for discrepancies in representation of minority groups in tech startups and discuss programs to rectify this discrepancy. Discrepancies include fewer business connections, lack funding, prejudice (exemplified by study conducted by Milkman and colleagues). 
Jones, Z. (2017). African Americans, STEM, and Entrepreneurship: A Study of Factors That Influence African Americans to Pursue Entrepreneurship in STEM Fields (Doctoral dissertation).

- The goal of this resource is to examine the educational backgrounds of high technology African American entrepreneurs and the factors of STEM programs that influence STEM-educated graduates to pursue high tech entrepreneurship.

Shelton, L.M. \& Minniti, M. (2018). Enhancing product market access: Minority entrepreneurship, status leveraging, and preferential procurement programs. Small Bus Econ, 50 (3), 481-498. https://doi.org/10.1007/s11187-017-9881-7

- "Access to product markets is a key barrier faced by minority entrepreneurs. Preferential procurement programs, which include government set-asides and commercial supplier diversity initiatives, are intended to aid these entrepreneurs in overcoming this barrier. Although the first programs resulted in minimal improvements due to design flaws and poor oversight, some recent initiatives have been redesigned to address these inadequacies. Using a qualitative approach, we examine the impact of these programs on product market access and present a conceptual model of their effect on the opportunity identification, evaluation, and exploitation of Black and Hispanic entrepreneurs. Our analysis suggests that preferential procurement programs may expand product market access by improving the information available to entrepreneurs and by altering the incentives of key resource providers. As a result, these programs may actually enable some minority entrepreneurs to achieve rapid expansion (high-growth entrepreneurs) and others to overcome personal limitations and establish viable enterprises (lower growth entrepreneurs) by leveraging their minority status."

Talbot, A. Study finds entrepreneurship training better for women, minorities. April 7, 2017 University of Western Ontario.

- "The study, Creating Entrepreneurs: The Impact of Entrepreneurship Programs on Minorities, indicates women and minorities are more likely to see benefits from entrepreneurship training."

Study finds refugee entrepreneurship has significant economic benefit. March 23, 2017, University of Technology.

- "Refugee entrepreneurs have the potential to make a significant economic contribution, with a new study of a pilot start-ups program showing their ability to 
generate jobs, tax revenue and a significant reduction in welfare support."

Quality Education for Minorities (QEM) Network. (2009, November). Report on the Mentoring Workshop for Underrepresented Minority Undergraduate Engineering_ Students and Faculty/Staff Advisors.

- With support from NSF's Directorate for Engineering, the goal of this workshop was to increase the participants' understanding of the roles that faculty and peer mentoring can play in enhancing the academic and professional outcomes of undergraduate engineering majors who are members of underrepresented minority groups.

\section{Media Resources}

The AWARE Project

\section{Visit the web version of this article to view interactive content.}

\section{THE AWARE PROJECT}

- The SBIR \& STTR Programs are one of the largest sources of early stage technology financing in the United States. The AWARE project, funded with a National Science Foundation pilot award, captured researchers commercialization journeys through interviews in order to help other women and minority scientists navigate entrepreneurship. You can watch these interviews here: https://www.foxchase.org/gmap_r4/emerging-areas/sbirsttr

AWARE Project YouTube Channel

\section{Acknowledgements}

The authors would like to express their thanks to the entrepreneurs and innovation thought leaders that participated in the AWARE project and whose insights are shared in this chapter. 
The contents of this chapter represent the opinions of the chapter authors and editors. The contents should not be construed as legal advice. The contents do not necessarily represent the official views of any affiliated organizations, partner organizations, or sponsors. For programs or organizations mentioned in this chapter, the authors encourage the reader to directly contact the relevant organization for additional information.

\section{Citations}

1. Etzkowitz, Henry, and Marina Ranga. "Gender Dynamics in Science and Technology: From the 'Leaky Pipeline' to the 'Vanish Box.'” Cahiers Economiques de Bruxelles, vol. 54, no. 2-3, Jan. 2011, pp. 131-47.

2. Christin Landivar, Liana. "Disparaties in STEM Employment by Sex, Race, and Hispanic Origin.” United States Census Bureau, 30 Sept. 2018, https://www.census.gov/library/publications/2013/acs/acs-24.html. 3. Noonan, Ryan. “Women in STEM: 2017 Update. ESA Issue Brief \#06-17.” US Department of Commerce, US Department of Commerce. 1401 Constitution Avenue NW, Washington, DC 20230. Tel: 202-482-2000; Web site: http://www.commerce.gov, Nov. 2017, http://files.eric.ed.gov/fulltext/ED590906.pdf.

4. Olsen, Dana. "Female-Founded, VC-Funded: The Numbers behind Venture Investment in Women." PitchBook, 15 Mar. 2017, https://pitchbook.com/news/articles/female-founded-vc-funded-the-numbers-behindventure-investment-in-women-datagraphic. $\doteq$

5. Mervis, Jeffrey. "Funding. NIH Program Fails to Launch Blacks in Biotech." Science, vol. 350, no. 6263, Nov. 2015, p. 896, doi:10.1126/science.350.6263.896. 6. Howe, Samantha A., et al. "Academic Women: Overlooked Entrepreneurs." Association of American Colleges \& Universities, vol. 16, no. 2, Apr. 2014, https://www.aacu.org/publications-research/periodicals/academic-women-overlookedentrepreneurs. $\doteq$

7. Million Women Mentors Entrepreneurship Initiative Mentoring Program. 2018, https://www.millionwomenmentors.com/sites/default/files/resources/MWMEI\%20Mentoring\%20Program rev3.pdf. $\doteq$ 
8. Valantine, Hannah, and Christy I. Sandborg. "Changing the Culture of Academic Medicine to Eliminate the Gender Leadership Gap: 50/50 by 2020." Academic Medicine: Journal of the Association of American Medical Colleges, vol. 88, no. 10, Oct. 2013, pp. 1411-13, doi:10.1097/ACM.0b013e3182a34952. 9. Nager, Adams, et al. "The Demographics of Innovation in the United States." SSRN, Feb. 2016, doi:10.2139/ssrn.3066060. 10. U.S. Small Business Administration Office of Advocacy. Minority STEM Entrepreneurs. 2016, https://www.sba.gov/sites/default/files/FIN_STEM_4 2016.pdf. $\Xi$

11. Abreu, Maria, and Vadim Grinevich. "Gender Patterns in Academic Entrepreneurship." The Journal of Technology Transfer, vol. 42, no. 4, Aug. 2017, pp. 763-94, doi:10.1007/s10961-016-9543-y..

12. Ding, Waverly W., et al. "Gender Differences in Patenting in the Academic Life Sciences." Science, vol. 313, no. 5787, Aug. 2006, pp. 665-67, doi:10.1126/science.1124832. $\uplus$ 13. Castillo, Alejandra. "The Case for Inclusive Innovation: Minority Entrepreneurship and America’s Economic Future." State of Black America, http://soba.iamempowered.com/case-inclusive-innovation-minority-entrepreneurshipand-america\%E2\%80\%99s-economic-future. Accessed 14 Aug. 2019. 14. Xie, Yu, and Kimberlee A. Shauman. Women in Science: Career Processes and Outcomes. Harvard University Press, 2005, https://www.hup.harvard.edu/catalog.php?isbn=9780674018594.. 15. Bahn, Kate, et al. "A Progressive Agenda for Inclusive and Diverse Entrepreneurship." Center for American Progress, 13 Oct. 2016, https://www.americanprogress.org/issues/economy/reports/2016/10/13/146019/aprogressive-agenda-for-inclusive-and-diverse-entrepreneurship $\perp . \triangleq$ 16. DeTienne, Dawn R., and Gaylen N. Chandler. "Opportunity Identification and Its Role in the Entrepreneurial Classroom: A Pedagogical Approach and Empirical Test." Academy of Management Learning \& Education, vol. 3, no. 3, Academy of Management, Sept. 2004, pp. 242-57, doi:10.5465/amle.2004.14242103. 17. Morgan, Rosemary, et al. "The Foundation and Consequences of Gender Bias in Grant Peer Review Processes." CMAJ: Canadian Medical Association Journal = 
Journal de l'Association Medicale Canadienne, vol. 190, no. 16, Apr. 2018, pp. E48788, doi:10.1503/cmaj.180188.

18. Carnes, Molly, et al. "NIH Director's Pioneer Awards: Could the Selection Process Be Biased against Women?” Journal of Women's Health , vol. 14, no. 8, Oct. 2005, pp. 684-91, doi:10.1089/jwh.2005.14.684.

19. Shavers, Vickie L., et al. "Barriers to Racial/ethnic Minority Application and Competition for NIH Research Funding." Journal of the National Medical Association, vol. 97, no. 8, Aug. 2005, pp. 1063-77, https://www.ncbi.nlm.nih.gov/pubmed/16173321.

20. Check Hayden, Erika. "Racial Bias Continues to Haunt NIH Grants.” Nature, vol. 527, no. 7578, Nov. 2015, pp. 286-87, doi:10.1038/527286a.

21. Reardon, Sara. "NIH to Probe Racial Disparity in Grant Awards." Nature, 21 Aug. 2014, doi:10.1038/512243a.

22. Fältholm, Ylva, et al. "Academic Entrepreneurship: Gendered Discourses and Ghettos." International Journal of Innovation and Technology Management, vol. 5, no. 1 , June 2010, doi:10.4067/S0718-27242010000100004.

23. Lyons, Elizabeth, and Laurina Zhang. "The Impact of Entrepreneurship Programs on Minorities." The American Economic Review, vol. 107, no. 5, May 2017, pp. 303-07, doi:10.1257/aer.p20171008. 